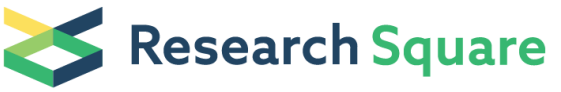 \\ Preprints are preliminary reports that have not undergone peer review. They should not be considered conclusive, used to inform clinical practice, or referenced by the media as validated information.
}

\section{Lymphocytopenia and neutrophilia deteriorate at the lowest oxygenation index timepoint in COVID-19 patient}

\section{Wei-jun Hong}

Department of Neurology, Taizhou Hospital of Zhejiang Province, Wenzhou Medical University, Linhai, Zhejiang, China

\section{Yi-wen Xu}

The First Clinical Medical College, Wenzhou Medical University, Wenzhou, Zhejiang, China

Wei-ling Li

Department of Neurology, Taizhou Hospital of Zhejiang Province, Wenzhou Medical University, Linhai, Zhejiang, China

\section{Chun-qiang Xu}

Department of Neurology, Taizhou Hospital of Zhejiang Province, Wenzhou Medical University, Linhai, Zhejiang, China

\section{Xiao-fei Hu}

Department of Neurology, Taizhou Hospital of Zhejiang Province, Wenzhou Medical University, Linhai, Zhejiang, China

\section{Mei-xian Zhang}

Public Experiment Center, Medical Research Center, Taizhou Hospital of Zhejiang Province, Linhai, Zhejiang, China

Hui-hui Xu

Laboratory of Gynecologic Oncology, Medical Research Center, Taizhou Hospital of Zhejiang Province, Wenzhou Medical University, Linhai, Zhejiang, China

\section{En Wang}

Department of Neurology, Taizhou Hospital of Zhejiang Province, Wenzhou Medical University, Linhai, Zhejiang, China

\section{Shao-fa Ke}

Department of Neurology, Taizhou Hospital of Zhejiang Province, Wenzhou Medical University, Linhai, Zhejiang, China

Xiao-ping Jin ( $\square$ liuxc5941@enzemed.com)

Department of Neurology, Taizhou Hospital of Zhejiang Province, Wenzhou Medical University, Linhai, Zhejiang, China

Gang Wu ( $\nabla$ weichen_star@126.com)

Department of Neurology, Taizhou Hospital of Zhejiang Province, Wenzhou Medical University, Linhai, Zhejiang, China

Xi-chang Liu ( $\square$ jinxp@enzemed.com )

Department of Neurology, Taizhou Hospital of Zhejiang Province, Wenzhou Medical University, Linhai, Zhejiang, China

\section{Research Article}

Keywords: COVID-19, oxygenation index, lymphocytopenia, neutrophilia, glucocorticoids

Posted Date: June 30th, 2020

DOl: https://doi.org/10.21203/rs.3.rs-37626/v1

License: (-) (1) This work is licensed under a Creative Commons Attribution 4.0 International License. Read Full License 


\section{Abstract}

\section{Background}

Coronavirus disease 2019 (COVID-19) spread throughout the world and caused hundreds of thousands of infected people to death. However, the pathogenesis of severe acute respiratory syndrome coronavirus-2 (SARS COV-2) is poorly understood. The objective of this study is to retrospectively explore the pathogenesis of COVID-19 from clinical laboratory findings, taking disease progression into account.

\section{Methods}

A single-centered, retrospective study was carried out, which included moderate $(n=76)$ and severe COVID-19 cases $(n=22)$. The difference of laboratory findings from blood routine examination and hepatorenal function test were retrospectively evaluated between the state of moderate and severe. The disease progression was indicated by oxygenation index.

\section{Results}

Age is a risk factor for disease progression from moderate to severe. Lymphocytopenia, neutrophilia, liver and kidney function decreasement occurred in severe patients on admission, compared with moderate patients. Lymphocytopenia and neutrophilia deteriorated at the lowest oxygenation index timepoint in the severe patients. And the oxygenation index was associated with ratio of lymphocyte and neutrophil in COVID-19 patients.

\section{Conclusions}

Lymphocytopenia and neutrophilia, which deteriorate in the progression of severe patients, are the main pathogenesis of COVID-19. More measures need to be taken to control lymphocytopenia and neutrophilia in severe COVID-19. Oxygenation index presented potentiality as predictor on the progression of COVID-19.

\section{Background}

COVID-19 spreads throughout the world and has a mortality rate of about 7.1\%[1](WHO, 2020). Preliminary data indicates that COVID19 can produce acute respiratory distress syndrome (ARDS), which is the leading cause of death. However up to now, the pathogenesis by which SARS-COV-2 triggers ARDS is poorly understood.

The aim of this study is to retrospectively explore the pathogenesis of COVID-19 from clinical laboratory findings, taking disease progression into account. The laboratory findings from our hospital were collected and a retrospective study of the differences in neutrophil, lymphocyte and so on during the moderate and most severe phases of COVID-19 was carried out. As a key lung function indicator, the oxygenation index was chosen as an indicator of the disease progression.

\section{Methods}

\section{Study design and participants}

This single-center, retrospective study was carried out at Taizhou hospital of Zhejiang province (Zhejiang, China). This hospital was specifically set up for the treatment of COVID-19 patients. We retrospectively recruited patients seen at the hospital between January 23, 2020 and February 27, 2020 and diagnosed with COVID-19 according to WHO's interim guidelines. These participants had been treated and discharged from hospital. The patients were considered to have moderate disease if they displayed fever, respiratory tract symptoms, or imaging evidence of pneumonia. Patients were considered severe cases if their resting respiratory rate was $>30$ per minute, oxygen saturation was below $93 \%$ without oxygen, or oxygenation index (PAO2/FiO2) or multiple pulmonary lobes showed $>50 \%$ disease progression within 48 hours of imaging [2].

\section{Data Collection}

We reviewed clinical electronic medical records, nursing records, laboratory results, and radiological examinations for all patients with confirmed SARS-CoV-2 infection. Demographic data (age, sex, body weight), medical history, exposure history, underlying conditions, 
symptoms, laboratory results and treatment (respiratory support, antiviral therapy, corticosteroid therapy, immunoglobulin and vitamin $\mathrm{C}$, etc.) were collected. Data were reviewed by a trained team of physicians.

\section{Laboratory confirmation}

Sputum and throat swab specimens collected from all patients at admission were analyzed RT-qPCR for SARS-CoV-2 RNA within 3 hours of collection, using novel coronavirus (2019-nCoV) nucleic acid detection kit (Shanghai Zhijiang Biotechnology Co., China) by following the manufacturer's instructions. The primers used target SARS-CoV-2 RdRp, N and E genes. Samples were considered SARSCOV-2 positive if they were RdRp positive and positive for either the $\mathrm{N}$ or $\mathrm{E}$ gene. Where only the RdRp gene was positive, the test was repeated and the sample was considered SARS-COV-2 positive if both tests returned positive. Samples were considered SARS-COV-2 negative if they were negative for all 3 genes. Conditions for the amplifications were $45^{\circ} \mathrm{C}$ for $10 \mathrm{~min}, 95^{\circ} \mathrm{C}$ for 3 min, followed by 45 cycles of $95^{\circ} \mathrm{C}$ for $15 \mathrm{~s}$ and $58^{\circ} \mathrm{C}$ for $30 \mathrm{~s}$.

\section{Patients' treatment}

Patients were treated with the antiviral agents (lopinavir/Ritonavir oral solution or arbidol). Nebulized recombinant interferona2b (rIFNa2b) was given at admission for about 10 days $\left(5 \times 10^{6} \mathrm{IU}\right.$, bid). Patients were randomly orally administered with vitamin $\mathrm{c}$ at a dose of 200mg, 3 times daily. Low dose of corticosteroid (methylprednisolone, 12-50mg daily for 5-7 days), and immunoglobulin (for 2-3 days) were administered in case of symptom deterioration. Nasal cannula oxygen support was given to patients depending on the severity of hypoxaemia. Patients with elevated inflammatory markers were treated with antibiotics (oral or intravenous). Patients with hepatic insufficiency indicated by ALT or AST were given reduced glutathione, compound ammonium glycyrrhizinate, diaminonium glycyrrhizate or bicyclol. Renal insufficient patients were treated with reduced glutathione or compound a-ketoacid. To monitor viral clearance, SARS-CoV-2 tests were done before hospital discharge.

\section{Statistical analysis}

Continuous variables were expressed as median (IQR) and compared using student's t test if data were normally distributed or otherwise, Mann-Whitney U test. Categorical variables were expressed as proportions (\%) and compared by $\chi^{2}$ test or Fisher's exact test when the data was limited between moderate and severe patients, or between the most severe timepoint and hospital discharge. Pearson correlation analysis was conducted to assess the association of oxygenation index with lymphocytopenia and neutrophilia. Linear regression was conducted to explore which factor is responsible for lowered oxygenation index. Tests were two-sided with significance set at $a=<0.05$. Data analysis was done on SPSS software, version 16.0 (SPSS Inc).

\section{Results}

\section{Demographics and baseline characteristics of patients with severe COVID-19}

98 hospitalized patients, laboratory confirmed to be SARS-COV-2 positive, were included in the study. The average age for the participants was 45.8 years (Std.Error (SE), 1.4). Of these, 58 (59.2\%) were male. 76 (78.6\%) of the participants were considered to be moderate cases, while 22 (22.4\%) were considered to be severe cases (Table 1). The median duration from symptom onset to hospital admission, hospital length of stay (HLOS) and clinic course were 6 days (IQR, 5), 15.6 days (IQR, 11), and 21.7 days (IQR, 9), respectively. Of the 98 patients, $32(32.7 \%)$ had 1 or more comorbidities. Hypertension [13 (13.3)], diabetes [6(6.1)], cancer [4(4.1)], and chronic liver disease [3(3.1)] were the most common underlying conditions (Table 1).

Compared with moderate cases, the severe patients were significantly older [average age, 55.1 years (SE, 2.2) vs 43.1 years (SE, 1.5), $P<0.001]$. Relative to moderate cases, severe cases were associated with longer HLOS and clinic course [median, 20.5 days (IQR, 8.5) vs 13 days (IQR, 11.0), $P=0.001 ; 26.5$ days (IQR, 14.3) vs 19.5 days (IQR, 8.8), $P<0.001$, respectively]. Relative to moderate cases, significantly more severe patients were treated with antibacterial agents, glucocorticoids and immunoglobulin [12(54.5\%) vs $20(26.3 \%), P=0.013 ; 17(77.3 \%)$ vs $4(5.3 \%), P<0.001 ; 14(63.6 \%)$ vs $2(2.6 \%), P<0.001$, respectively]. There were no differences in the percentage of vitamin $C$ therapy given to moderate and severe cases [7(31.2\%) vs 17(22.4\%)] (Table 1$)$.

\section{Deterioration of lymphocytopenia and neutrophilia at the lowest oxygenation index timepoint}


COVID-19 symptoms continued to progress after hospital admission. During hospital stay, the patients underwent multiple oxygenation index assays, a key lung function indicator. The lowest oxygenation index was chosen as the most severe timepoint. The laboratory results for tests done at admission, at the most severe timepoint and before discharge were analyzed. This analysis revealed that laboratory results for moderate cases remain relatively stable between the admission and the lowest oxygenation timepoint. At admission, the lymphocyte ratio in severe cases was significantly lower than in moderate cases [median, 23.6 (IQR, 20.85) vs 25.75 (IQR, 9.8), $P=0.041$ ], while the neutrophil ratio was higher in severe cases [median, 66.1 (IQR, 27.25) vs 65 (IQR, 14.43), $P=0.039]$. At the most severe timepoint, the lymphocyte ratio in severe cases decreased sharply, and was lower than the lymphocyte ratio in moderate cases [median, 11.55 (IQR, 15.58) vs 25.5(IQR, 13.95), $P<0.001$ ]. Neutrophil ratio and white-cell counts were significantly higher than in moderate cases [median, 81.25 (IQR, 21.8) vs 66.1(IQR, 16.12), $P<0.001 ; 8.05$ (IQR, 4.93) vs 6.0(IQR, 2.05), $P=0.006$, respectively] (see Table 2).

At hospital discharge, oxygenation index, lymphocytopenia and neutrophilia were significantly improved after multiple rounds of treatment $(P<0.001)$, when compared to the most severe timepoint. However, neutrophil ratio and white-cell counts in severe cases remained higher than in moderate cases [median, 66.3 (IQR, 15.38) vs 62.85 (IQR, 11.9), P=0.002; 6.0(IQR, 1.7) vs 6.95(IQR, 3.83), $P<0.001$, respectively]. Notably, the platelet count in severe cases was significantly lower than in moderate cases [median, 205.5 (IQR, 100.25) vs 270 (IQR, 100.5), $P=0.003$ ] (see Table 2).

Liver and kidney functions were monitored by analyzing alanine and aspartate aminotransferase levels, as well as creatinine clearance rate. This analysis revealed that liver and kidney function in the severe cases were poorest at admission but improved gradually. Relative to the moderate cases, lower levels of uric acid, an endogenous free radical scavenger and a major antioxidant in plasma[3], were observed in severe cases at the lowest oxygenation index timepoint [median, 224 (IQR, 128) vs 257 (IQR, 139.5), $P=0.028$ ] (see Table 2). However, linear regression analysis suggests that the lower uric acid levels might be age and sex related and not oxygenation index dependent (uric acid $=468.65-1.721$ age -56.244 sex -0.07 oxygenation index, Adjusted $\mathrm{R}$ Square $=0.098$, $P=0.036,0.009,0.295$ for age, sex, oxygenation index, respectively).

\section{Association of oxygenation index with lymphocytopenia and neutrophilia}

To evaluate the relationship of oxygenation index with lymphocytopenia and neutrophilia, the pearson correlation analysis and linear regression analysis were carried out. The association of oxygenation index with lymphocytopenia and neutrophilia were demonstrated by pearson correlation analysis of the values at the most severe timepoint ( $r=0.465$ with neutrophil ratio, $P<0.001$; $\mathrm{r}=-0.461$ with lymphocyte ratio, $P<0.001$ ) (Fig 1). Linear regression analysis showed that age and liver function were the factors that influenced the oxygenation index levels (oxygenation index $=790.777-39.816$ age-2.799sex-1.627body weight-2.385ALT+0.536 AST0.404 creatinine clearance rate- 2.672 comorbidities, Adjusted R Square $=0.141, P=0.006,0.043,0.226,0.299,0.739,0.563,0.912$ for age, ALT, sex, body weight, AST, creatinine clearance rate, comorbidities, respectively). Syphilis, gout, hypothyroidism were not included in comorbidities here as neither of them was reported to be related with the risk of COVID-19 in the literature.

\section{Discussion}

COVID-19, which spread rapidly and has been considered as a global pandemic, has a fatality rate of about 7.1\% fatality[1]. However, its pathogenesis is poorly understood. We have successfully treated 98 SARS-CoV-2 positive patients displaying moderate or severe symptoms and all have been discharged from hospital. Findings from the retrospective analysis of these patient's primary clinical data can help to better understand the COVID-19 pathogenesis. Because dyspnea and subsequent ARDS [4, 5] is the main complication from COVID-19, we chose the lowest oxygenation index as the most severe COVID-19 timepoint. We observed that lymphocytopenia and neutrophilia were the main features of the disease at the most severe timepoint and COVID-19 progression is accompanied by a deteriorating lymphocytopenia and neutrophilia. Several other studies have also shown that lymphocytopenia and neutrophilia were the clinical charactertistics in critical patient or nonsurvivors, compared to the noncritical or survivors [5-8]. Nevertheless, this is the first study takes disease progression into account indicating by the oxygenation index.

Oxygenation index was shown to be related with lymphocytopenia and neutrophilia after pearson correlation analysis in this study and also with radiographic score in [9]. Oxygenation index presented potentiality as predictor on the progression of COVID-19. Because of small sample size and lack of image data, the criterion of oxygenation index for COVID-19 deterioration was not achieved. Some COVID-19 patients with "silent hypoxemia" deteriorate rapidly without signs of respiratory distress [10]. Moreover, oxygenation index is easy to calculate and suitable for clinical application in admission units during a pandemic. It is recommended to routinely

Page $4 / 9$ 
monitor the oxygenation index and increase oxygen delivery once it decreases. As age and ALT influenced the oxygenation index levels shown in linear regression analysis, it is needed to pay attention to the liver function in elderly patients [11].

Our data implies four means of COVID-19 pathogenesis: (1) Like SARS-CoV [12], SARS-CoV-2 invades and destroys lymphocytes [13]. (2) Neutrophils, as part of the innate immune system, increase sharply to help clear exogenous virus. At the same time, high levels of reactive oxygen species are produced, which may cause injury to the lung epithelial-endothelial barrier[14]. (3) A cytokine storm triggered by the destroyed lymphocytes and hyperactive neutrophils might occur in severe COVID-19 [15, 16]. (4) An overactive immune response causes diffuse alveolar damage, airway inflammation and increased secretions overflowed from the alveoli, leading to the airways blockage and dyspnea $[17,18]$. A subset of patients specially with comorbidities such as hypertension or diabetes develop acute respiratory distress syndrome (ARDS), multiple organ failure and/or septic shock, which are high risk indication of death.

Interventions that manage these COVID-19 consequences should be beneficial in clinic practice. Clinical applications such as thymosin and gamma globulin will improve the COVID-19 patients' poor immune function [19]. Therapeutic strategies targeting neutrophilia by reducing neutrophil numbers, blocking neutrophil activation or blocking neutrophil-derived mediators will provide new options for clinical SARS-CoV-2-induced pneumonia[20]. Treatment options for patients with severe inflammation include steroids, intravenous immunoglobulin, selective cytokine blockers (such as anakinra or tocilizumab [21,22]) and JAK inhibitors. A multicenter randomized controlled trial of tocilizumab (IL-6 receptor blocker) has been approved for clinical trials in patients with covid-19 pneumonia and elevated IL-6 in China (ChiCTR2000029765).

In our hospital, various measures were taken to treat COVID-19 patients and their benefits in inhibition of lymphocytopenia and neutrophilia and subsequent inflammatory storm deserve to be discussed. Interferon interferes with virus replication and transmission through mechanisms such as reducing cell metabolism or cytokine secretion which could promote the activation of adaptive immunity and it may upscale treatment in early stages of COVID-19 infection [23]. The results that SARS-CoV-2 failed to induce IFNs expression supports that exogenous IFN treatment might be beneficial for COVID-19[24]. On the other hand, interferon stimulates gene expression of ACE2, SARS-CoV-2 receptor, in human airway epithelial cells. Whether interferon is net beneficial or detrimental in COVID-19 needs studied [25].

Glucocorticoid is a widely used and effective anti-inflammatory and immunosuppressive agent. Low dose of glucocorticoids was used for a few days here, which was not associated with severe sequelae, when the oxygenation index fell sharply. This treatment could be critical in reversing COVID-19 complications [26, 27]. Deteriorating severe patients also received immunoglobulin which could neutralize the pathogens, block the receptors on virus-targeted cells and inhibit production of inflammatory factors. Immunoglobulin was reported to reduce HLOS and 28-day mortality of patients with severe COVID-19 pneumonia [28]. In lymphocytopenia situation, patients were seldom treated with thymosin. However, thymosin was reported to reverses $T$ cell exhaustion in a retrospective study [19]. Vitamin C is supposed to alleviate COVID-19 symptoms by scavenging reactive oxygen and nitrogen species and also modulation of the immune system. However, any impact of vitamin C administration on lymphocytopenia, neutrophilia, HLOS or clinic course of the disease was not observed, upon analysis of differences of laboratory findings between the treated and untreated group (Supplementary table 1.) and regression of vitamin $\mathrm{c}$ to changes of laboratory results. This may be due to the short metabolic half-life and low dose of vitamin $C$ used [29].

Considering the information described above, the deteriorating lymphocytopenia and neutrophilia was observed in the progression of severe COVID-19 patients. Oxygenation index presented potentiality as predictor on the progression of COVID-19. These findings indicate that the oxygenation index should be routinely monitored and measures need to be taken to control lymphocytopenia, neutrophilia and the resulting cytokine storm. Symptomatic treatments such as low dose of glucocorticoids and immunoglobulin possess possible benefit on COVID-19 amelioration.

This study has several limitations. First, the sample size is small. Only 22 severe patients were included. Second, image data was not collected. Because of the two shortcomings, the causal relationship and criterion of decreasement of oxygenation index for COVID-19 deterioration was not achieved. Third shortcoming comes from the retrospective observational nature of this study, so it is difficult to address the relationships between COVID-19 amelioration and symptomatic therapy such as glucocorticoids and vitamin c.

\section{Tables}


Table 1. Demographics and baseline characteristics of patients with COVID-19

\begin{tabular}{|c|c|c|c|c|}
\hline & $\begin{array}{c}\text { Total } \\
(\mathrm{n}=98)\end{array}$ & $\begin{array}{c}\text { Moderate cases } \\
(\mathrm{n}=76)\end{array}$ & $\begin{array}{c}\text { Severe cases } \\
(\mathrm{n}=22)\end{array}$ & $P$ Value \\
\hline Age, mean \pm Std.Error, y & $45.8 \pm 1.4$ & $43.1 \pm 1.5$ & $55.1 \pm 2.2$ & 0.000 \\
\hline \multicolumn{5}{|l|}{ Sex } \\
\hline Male, $\mathrm{n}(\%)$ & $58(59.2)$ & $45(60)$ & $12(54.5)$ & 0.65 \\
\hline Body weight, median (IQR), kg & $65(16.5)$ & $65(15.5)$ & $70(17.0)$ & 0.13 \\
\hline \multicolumn{5}{|l|}{ Comorbidities } \\
\hline Hypertension, $\mathrm{n}(\%)$ & $13(13.3)$ & $7(9.2)$ & $6(27.3)$ & 0.065 \\
\hline Diabetes, $\mathrm{n}(\%)$ & $6(6.1)$ & $3(3.9)$ & $3(13.6)$ & 0.24 \\
\hline Malignancy, n(\%) & $4(4.1)$ & $3(3.9)$ & $1(4.5)$ & 1.000 \\
\hline Chronic liver disease, $\mathrm{n}(\%)$ & $3(3.1)$ & $3(3.9)$ & $0(0)$ & 1.0 \\
\hline Chronic kidney disease, $\mathrm{n}(\%)$ & $2(2.0)$ & $1(1.3)$ & $1(4.5)$ & 0.40 \\
\hline Hypothyroidism, n(\%) & $1(1.0)$ & $1(1.3)$ & $0(0)$ & 1.0 \\
\hline Syphilis, n(\%) & $1(1.0)$ & $0(0)$ & $1(4.5)$ & 0.22 \\
\hline Chronic bronchitis, $\mathrm{n}(\%)$ & $1(1.0)$ & $1(1.3)$ & $0(0)$ & 1.0 \\
\hline Gout, n(\%) & $1(1.0)$ & $0(0)$ & $1(4.5)$ & 0.22 \\
\hline Pregnancy, n(\%) & $1(1.0)$ & $1(1.3)$ & $0(0)$ & 1.0 \\
\hline \multicolumn{5}{|l|}{ Drug therapy } \\
\hline Antiviral agents, n(\%) & $98(100)$ & $76(100)$ & $22(100)$ & 1.0 \\
\hline $\mathrm{rIFN} \alpha 2 \mathrm{~b}, \mathrm{n}(\%)$ & $98(100)$ & $76(100)$ & $22(100)$ & 1.0 \\
\hline Glucocorticoids, n(\%) & $21(21.4)$ & $4(5.3)$ & $17(77.3)$ & 0.000 \\
\hline Immunoglobulin, n(\%) & $16(16.3)$ & $2(2.6)$ & 14(63.6) & 0.000 \\
\hline Vitamin $\mathrm{C}, \mathrm{n}(\%)$ & $24(24.5)$ & $17(22.4)$ & $7(31.2)$ & 0.36 \\
\hline Antibacterial agents, $\mathrm{n}(\%)$ & $32(32.7)$ & $20(26.3)$ & $12(54.5)$ & 0.013 \\
\hline Onset of symptom to Hospital admission, median (IQR), d & $6.0(5.0)$ & $5.0(5.0)$ & $6.5(7.8)$ & 0.40 \\
\hline HLOS, median (IQR), d & 15.6(11.0) & $13.0(11.0)$ & $20.5(8.5)$ & 0.001 \\
\hline Clinic course, median (IQR), d & $21.7(9)$ & $19.5(8.8)$ & $26.5(14.3)$ & 0.000 \\
\hline
\end{tabular}

$P$ values comparing moderate cases and severe cases are from $\chi \square$ test, Fisher's exact test, Mann-Whitney U test or Student's t test. IQR, interquartile range.

Table 2. Laboratory results of patients infected with SARS CoV-2

\begin{tabular}{|c|c|c|c|c|c|c|c|c|c|c|}
\hline & $\begin{array}{l}\text { On } \\
\text { admission }\end{array}$ & & & At the lowest & xygenation inde & $x$ time & Discharge fro & a hospital & & \\
\hline & $\begin{array}{l}\text { Moderate } \\
\text { case }\end{array}$ & Severe case & $P$ Value & $\begin{array}{l}\text { Moderate } \\
\text { case }\end{array}$ & Severe case & $P$ Value & $\begin{array}{l}\text { Moderate } \\
\text { case }\end{array}$ & Severe case & $P$ Value $^{\mathrm{a}}$ & $P$ Value $^{\mathrm{b}}$ \\
\hline $\begin{array}{l}\text { Oxygenation } \\
\text { index }(\mathrm{mmHg})\end{array}$ & $452(105)$ & $329(149.5)$ & 0.000 & $452(121.75)$ & $234(72)$ & 0.000 & 481.5(273) & $374(98.5)$ & 0.002 & 0.000 \\
\hline Lactate $(\mathrm{mmol} / \mathrm{L})$ & $1.75(0.85)$ & $1.9(0.9)$ & 0.88 & $1.7(0.68)$ & $1.95(1.32)$ & 0.040 & $1.7(1.07)$ & $1.7(1.22)$ & 0.388 & 0.54 \\
\hline White-cell count $(\times 10 \square / L)$ & $5.3(2.05)$ & $5.5(3.75)$ & 0.79 & $6.0(2.05)$ & $8.05(4.93)$ & 0.006 & $6.0(1.7)$ & $6.95(3.83)$ & 0.000 & 0.21 \\
\hline Lymphocyte ratio (\%) & $25.75(9.8)$ & $23.6((20.85)$ & 0.041 & $25.5(13.95)$ & $11.55(15.58)$ & 0.000 & $25.3(9.03)$ & $19.9(15.75)$ & 0.459 & 0.000 \\
\hline Neutrophil ratio (\%) & $65(14.43)$ & $66.1(27.25)$ & 0.039 & $66.1(16.12)$ & $81.25(21.8)$ & 0.000 & $62.85(11.9)$ & $66.3(15.38)$ & 0.002 & 0.000 \\
\hline Platelet count $(\times 10 \square / \mathrm{L})$ & $209(62.5)$ & 185(128.5) & 0.23 & $217.5(73.25)$ & $230.5(111.25)$ & 0.57 & $270(100.5)$ & 205.5(100.25) & 0.003 & 0.001 \\
\hline $\begin{array}{l}\text { Alanine } \\
\text { aminotransferase(U/liter) }\end{array}$ & $18(17.75)$ & $30(24)$ & 0.032 & $18(17)$ & $28(20.25)$ & 0.005 & $20.5(22.5)$ & $26.5(15.5)$ & 0.136 & 0.27 \\
\hline $\begin{array}{l}\text { Aspartate } \\
\text { aminotransferase(U/liter) }\end{array}$ & $22(8.0)$ & $31(23.5)$ & 0.001 & $24(8.5)$ & $23.5(16.0)$ & 0.29 & $21.0(7)$ & $22.0(6)$ & 0.989 & 0.053 \\
\hline Total bilirubin $(\mu \mathrm{mol} / \mathrm{L})$ & $13.15(9.42)$ & $15.3(13.55)$ & 0.51 & $14.4(7.18)$ & $16.1(15.4)$ & 0.95 & $12.7(4.78)$ & $11.8(7.55)$ & 0.122 & 0.28 \\
\hline $\begin{array}{l}\text { Direct bilirubin } \\
(\mu \mathrm{mol} / \mathrm{L})\end{array}$ & $4.85(3.38)$ & $6.2(5.6)$ & 0.25 & $5.35(2.45)$ & $6.25(6.10)$ & 0.68 & $3.95(1.5)$ & $3.0(2.6)$ & 0.024 & 0.001 \\
\hline $\begin{array}{l}\text { Indirect bilirubin } \\
(\mu \mathrm{mol} / \mathrm{L})\end{array}$ & $8.15(5.85)$ & $9.1(7.6)$ & 0.67 & $9.0(5.5)$ & $10.20(7.78)$ & 0.90 & $8.7(3.93)$ & $8.15(5.02)$ & 0.239 & 0.91 \\
\hline Uric acid $(\mu \mathrm{mol} / \mathrm{L})$ & $266(128.75)$ & $252(170.5)$ & 0.23 & $257(139.5)$ & $224(128)$ & 0.028 & $273(116)$ & 269.5(95.25) & 0.040 & 0.29 \\
\hline Creatinine $(\mu \mathrm{mol} / \mathrm{L})$ & $77(22)$ & $73(21)$ & 0.77 & $78(20)$ & $73(23.75)$ & 0.38 & $76.5(21.25)$ & $69(17.5)$ & 0.242 & 0.036 \\
\hline $\begin{array}{l}\text { Blood urea } \\
\text { nitrogen(mmol/L) }\end{array}$ & $4.18(1.7)$ & $4.19(1.74)$ & 0.55 & $3.84(1.23)$ & $5.03(3.6)$ & 0.044 & $3.41(1.72)$ & $3.78(1.7)$ & 0.023 & 0.53 \\
\hline $\begin{array}{l}\text { Creatinine clearance } \\
\text { rate }(\mathrm{ml} / \mathrm{min})\end{array}$ & $101.5(22)$ & $86(19.5)$ & 0.003 & 102(15.75) & $86(18)$ & 0.021 & 103.5(28.75) & $92(18.5)$ & 0.135 & 0.52 \\
\hline
\end{tabular}

Data are showed as median (IQR). ${ }^{\mathrm{a}} P$ values comparing moderate cases and severe patients from Mann-Whitney U test. ${ }^{\mathrm{b}} P$ value comparing the lowest oxygenation index timepoint and discharge from hospital of all the patients.

\section{Abbreviations}


Covid-19, Coronavirus disease 2019;

SARS COV-2, severe acute respiratory syndrome coronavirus-2;

ALT, Alanine aminotransferase;

AST, Aspartate aminotransferase;

$\mathrm{IQR}$, interquartile range;

HLOS, hospital length of stay

\section{Declarations}

\section{Ethics approval and consent to participate}

This study was approved by the ethics commission of Zhejiang Province Taizhou Hospital. All data were anonymized to comply with the provisions of personal data protection legislation. Due to the retrospective nature of this study and due the fact that only historical medical data were collected, written informed consent was not required.

\section{Availability of data and materials}

The datasets used and/or analysed during the current study are available from the corresponding author on reasonable request.

\section{Competing interests}

The authors declare that they have no competing interests.

\section{Funding}

This research did not receive any specific grant from funding agencies in the public, commercial, or not-for-profit sectors.

\section{Author Contributions}

XCL, GW, XPJ conceived and designed the study. WJH, YWX, WLL, CQX, XFH did data collection. GW, MXZ, HHX performed data analysis. XPJ, SFK and EW provided resources. WJH and YWX wrote the original draft. XCL, GW, XPJ reviewed and edited the manuscript. WJH and YWX contributed equally to this paper. All authors read and approved the final manuscript.

\section{Acknowledgments}

We acknowledge all health-care workers involved in the diagnosis and treatment of patients in Taizhou city.

\section{References}

1. WHO, 19th,Mar,2020. Coronavirus disease 2019 (COVID-19)Situation Report. https://www.who.int/emergencies/diseases/novelcoronavirus-2019/situation-reports/. (Accessed 1st,May,2020).

2. Xu X-W, Wu X-X, Jiang X-G, Xu K-J, Ying L-J, Ma C-L, Li S-B, Wang H-Y, Zhang S, Gao H-N et al: Clinical findings in a group of patients infected with the 2019 novel coronavirus (SARS-Cov-2) outside of Wuhan, China: retrospective case series. BMJ 2020, 368:m606. doi: 10.1136/bmj.m606

3. Glantzounis GK, Tsimoyiannis EC, Kappas AM, Galaris DA: Uric acid and oxidative stress. Current pharmaceutical design 2005, 11(32):4145-4151. doi: 10.2174/138161205774913255

4. Zhang B, Zhou X, Qiu Y, Feng F, Feng J, Jia Y, Zhu H, Hu K, Liu J, Liu Z et al: Clinical characteristics of 82 death cases with COVID19. medRxiv 2020:2020.2002.2026.20028191. doi: 10.1101/2020.02.26.20028191

5. Huang C, Wang Y, Li X, Ren L, Zhao J, Hu Y, Zhang L, Fan G, Xu J, Gu X et al: Clinical features of patients infected with 2019 novel coronavirus in Wuhan, China. The Lancet 2020, 395(10223):497-506. 
6. Wang D, Hu B, Hu C, Zhu F, Liu X, Zhang J, Wang B, Xiang H, Cheng Z, Xiong Y et al: Clinical Characteristics of 138 Hospitalized Patients With 2019 Novel Coronavirus-Infected Pneumonia in Wuhan, China. Jama 2020:E1-9.

7. Yan L, Zhang H-T, Goncalves J, Xiao Y, Wang M, Guo Y, Sun C, Tang X, Jing L, Zhang M et al: An interpretable mortality prediction model for COVID-19 patients. Nature Machine Intelligence 2020. doi: 10.1038/s42256-020-0180-7

8. Zhao XY, Xu XX, Yin HS, Hu QM, Xiong T, Tang YY, Yang AY, Yu BP, Huang ZP: Clinical characteristics of patients with 2019 coronavirus disease in a non-Wuhan area of Hubei Province, China: a retrospective study. BMC infectious diseases 2020, 20(1):311.

9. Zhang X, Cai H, Hu J, Lian J, Gu J, Zhang S, Ye C, Lu Y, Jin C, Yu G et al: Epidemiological, clinical characteristics of cases of SARS-CoV-2 infection with abnormal imaging findings. International journal of infectious diseases : IJID : official publication of the International Society for Infectious Diseases 2020, 94:81-87.

10. Ottestad W, Seim M, Maehlen JO: COVID-19 with silent hypoxemia. Tidsskrift for den Norske laegeforening : tidsskrift for praktisk medicin, ny raekke 2020, 140(7). doi: 10.4045/tidsskr.20.0299

11. Feng G, Zheng KI, Yan QQ, Rios RS, Targher G, Byrne CD, Poucke SV, Liu WY, Zheng MH: COVID-19 and Liver Dysfunction: Current Insights and Emergent Therapeutic Strategies. Journal of clinical and translational hepatology 2020, 8(1):18-24.

12. Yang X, Yu Y, Xu J, Shu H, Xia Ja, Liu H, Wu Y, Zhang L, Yu Z, Fang M et al: Clinical course and outcomes of critically ill patients with SARS-CoV-2 pneumonia in Wuhan, China: a single-centered, retrospective, observational study. The Lancet Respiratory Medicine 2020:1-7. doi: 10.1016/S2213-2600(20)30079-5

13. Wang X, Xu W, Hu G, Xia S, Sun Z, Liu Z, Xie Y, Zhang R, Jiang S, Lu L: SARS-CoV-2 infects T lymphocytes through its spike protein-mediated membrane fusion. Cellular \& molecular immunology 2020:1-3. doi: 10.1038/s41423-020-0424-9

14. Short KR, Kroeze EJBV, Fouchier RAM, Kuiken T: Pathogenesis of influenza-induced acute respiratory distress syndrome. The Lancet Infectious Diseases 2014, 14(1):57-69.

15. Mehta P, McAuley DF, Brown M, Sanchez E, Tattersall RS, Manson JJ: COVID-19: consider cytokine storm syndromes and immunosuppression. The Lancet 2020. doi: 10.1016/S0140-6736(20)30628-0

16. Xu Z, Shi L, Wang Y, Zhang J, Huang L, Zhang C, Liu S, Zhao P, Liu H, Zhu L et al: Pathological findings of COVID-19 associated with acute respiratory distress syndrome. The Lancet Respiratory Medicine 2020. doi: 10.1016/S2213-2600(20)30076-X

17. Barton LM, Duval EJ, Stroberg E, Ghosh S, Mukhopadhyay S: COVID-19 Autopsies, Oklahoma, USA. American journal of clinical pathology 2020, 153(6):725-733. doi: 10.1093/ajcp/aqaa062

18. Liu Q, Wang RS, Qu GQ, Wang YY, Liu P, Zhu YZ, Fei G, Ren L, Zhou YW, Liu L: Gross examination report of a COVID-19 death autopsy. Fa yi xue za zhi 2020, 36(1):21-23.

19. Liu Y, Pang Y, Hu Z, Wu M, Wang C, Feng Z, Mao C, Tan Y, Liu Y, Chen L et al: Thymosin alpha 1 (Ta1) reduces the mortality of severe COVID-19 by restoration of lymphocytopenia and reversion of exhausted T cells. Clinical infectious diseases : an official publication of the Infectious Diseases Society of America 2020. doi: 10.1093/cid/ciaa630

20. Németh T, Sperandio M, Mócsai A: Neutrophils as emerging therapeutic targets. Nature Reviews Drug Discovery 2020, 19(4):253275.

21. Luo P, Liu Y, Qiu L, Liu X, Liu D, Li J: Tocilizumab treatment in COVID-19: a single center experience. Journal of Medical Virology 2020, Accepted Author Manuscript. doi: 10.1002/jmv.25801

22. Xu X, Han M, Li T, Sun W, Wang D, Fu B, Zhou Y, Zheng X, Yang Y, Li X et al: Effective treatment of severe COVID-19 patients with tocilizumab. Proceedings of the National Academy of Sciences of the United States of America 2020, 117(20):10970-10975.

23. Sallard E, Lescure FX, Yazdanpanah Y, Mentre F, Peiffer-Smadja N: Type 1 interferons as a potential treatment against COVID-19. Antiviral research 2020, 178:104791.

24. Chu H, Chan JF-W, Wang Y, Yuen TT-T, Chai Y, Hou Y, Shuai H, Yang D, Hu B, Huang X et al: Comparative replication and immune activation profiles of SARS-CoV-2 and SARS-CoV in human lungs: an ex vivo study with implications for the pathogenesis of COVID-19. Clinical Infectious Diseases 2020. doi: 10.1093/cid/ciaa410

25. Ziegler CGK, Allon SJ, Nyquist SK, Mbano IM, Miao VN, Tzouanas CN, Cao Y, Yousif AS, Bals J, Hauser BM et al: SARS-CoV-2 Receptor ACE2 Is an Interferon-Stimulated Gene in Human Airway Epithelial Cells and Is Detected in Specific Cell Subsets across Tissues. Cell 2020. doi: 10.1016/j.cell.2020.04.035 
26. Ye Q, Wang B, Mao J, Fu J, Shang S, Shu Q, Zhang T: Epidemiological analysis of COVID-19 and practical experience from China. J Med Virol 2020. doi: 10.1002/jmv.25813

27. Zhagn S, Li D, Chen H, Zheng D, Zhou Y, Chen B, Shi W, Lin R: [Dynamic inflammatory response in a critically ill COVID-19 patient treated with corticosteroids]. Zhejiang da xue xue bao Yi xue ban = Journal of Zhejiang University Medical sciences 2020, 49(2):220-226

28. Xie Y, Cao S, Dong H, Li Q, Chen E, Zhang W, Yang L, Fu S, Wang R: Effect of regular intravenous immunoglobulin therapy on prognosis of severe pneumonia in patients with COVID-19. The Journal of infection 2020. doi: 10.1016/j.jinf.2020.03.044

29. Fowler AA, 3rd, Truwit JD, Hite RD, Morris PE, DeWilde C, Priday A, Fisher B, Thacker LR, 2nd, Natarajan R, Brophy DF et al: Effect of Vitamin C Infusion on Organ Failure and Biomarkers of Inflammation and Vascular Injury in Patients With Sepsis and Severe Acute Respiratory Failure: The CITRIS-ALI Randomized Clinical Trial. Jama 2019, 322(13):1261-1270.

\section{Figures}



Figure 1

Association of oxygenation index with lymphocyte ratio and neutrophil ratio in COVID-19 patient. Left is changes of oxygenation index (purple), lymphocyte ratio (blue) and neutrophil ratio (orange) in moderate cases (dotted line) and severe cases (solid line). 1, On admission;2, Lowest oxygenation index timepoint;3,Discharge from hospital. Right is results of pearson correlation analysis of oxygenation index with lymphocyte ratio (upper) and neutrophil ratio (lower). Black circles, moderate cases; red circles, severe cases. $r$ = Pearson's coefficient; $P$, significance .

\section{Supplementary Files}

This is a list of supplementary files associated with this preprint. Click to download.

- Supplementarymaterial.docx 